\title{
Traumatic chemical oral ulceration: a case report and review of the literature
}

- Offers a detailed review of all aspects of traumatic chemical oral lesions.

- Reviews all substances encountered that cause damage to the oral mucosa.

- Gives practical information to all members of the oral health care team

\author{
C. Gilvetti, ${ }^{1}$ S. R. Porter ${ }^{2}$ and S. Fedele ${ }^{3}$
}

\begin{abstract}
A 34-year-old man experienced extensive oral ulceration as a consequence of attempted ingestion of sulphuric acid as part of an act of deliberate self harm. All oral lesions healed within 28 days after local and systemic therapy. Oral ulceration has many potential causes ranging from physical trauma to malignancy. Chemicals are a less common cause of traumatic ulceration. Most chemical burns are characterised by mild to moderate tissue damage that heals spontaneously within seven to 15 days without scarring.
\end{abstract}

\section{INTRODUCTION}

Oral ulceration has many potential causes ranging from physical trauma to malignancy. ${ }^{1}$ Most traumatic ulceration reflects local physical aetiologies such as a broken tooth or dental restoration, or trauma from an orthodontic or prosthodontic appliance. Chemicals are a less common cause of traumatic ulceration. Examples include local application of medications (eg aspirin), recreational drugs (cocaine), some materials commonly used by dentists, and non-pharmaceutical substances. ${ }^{2-4}$ We report a case of chemical oral ulceration as a result of an intentional suicidal acute exposure to sulphuric acid and we present a review of the literature concerning chemical oral ulceration.

\section{CASE REPORT}

A 34-year-old man was admitted to the thoracic surgery unit of Ascalesi Hospital Naples (Italy) because of dyspnoea. His parents reported that he had tried to commit suicide by stabbing himself in the chest and ingesting a caustic agent. The patient confirmed that he had tried to swallow sulphuric acid, but had spat it out because of

${ }^{1^{*}-3}$ Department of Oral Medicine, UCL Eastman Dental Institute, 256 Gray's Inn Road, London, WC1X 8LD

${ }^{*}$ Correspondence to: Dr Ciro Gilvetti

Email: cirogilvetti@ hotmail.it

\section{Refereed Paper}

Accepted 19 February 2010

DOI: 10.1038/sj.bdj.2010.295

${ }^{\circledR}$ British Dental Journal 2010; 208: 297-300

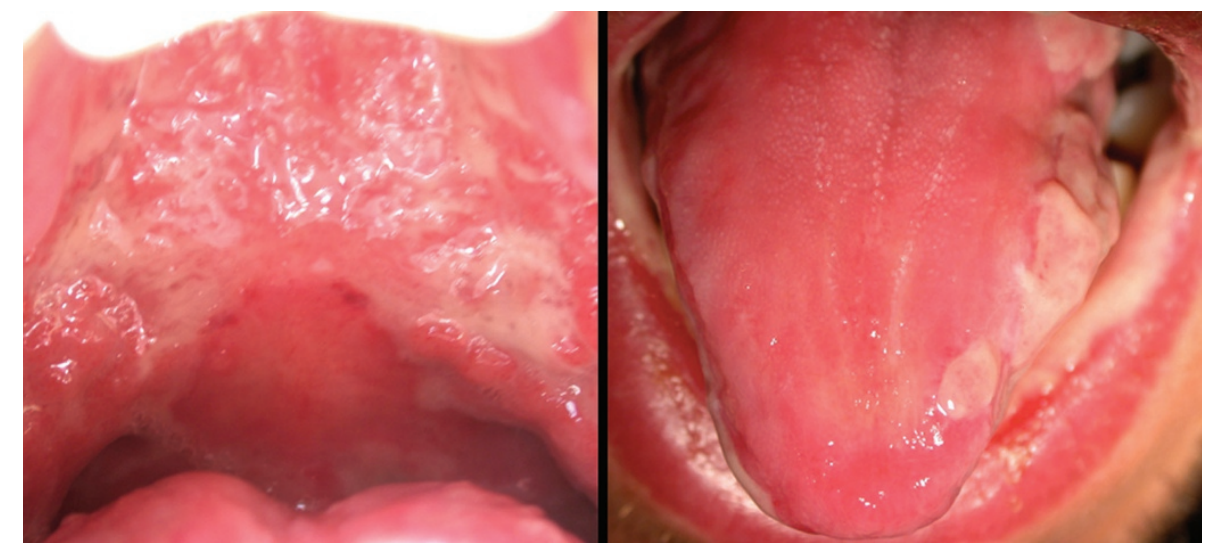

Fig. 1 Extensive ulceration of the palate and lateral aspects of tongue secondary to deliberate application of sulphuric acid

its strong irritant effect. Some of the acid had dropped onto his leg, causing immediate pain. He had then attempted to stab himself to death with a kitchen knife. His social history was unremarkable except for his job as a plumber, which explained why he had ready access to the sulphuric acid. Initial clinical examination had revealed an irregular superficial dermal erosion of his left leg and a penetrating thoracic injury in the third intercostal space. Immediate chest radiography and chest CT had demonstrated the typical features of left haemothorax. As the patient did not swallow the caustic agent he had no significant damage to the upper aerodigestive tract as shown on oesophagogastroduodenoscopy, although there was slight epiglottic oedema. Following emergency treatment, eight days later, the thoracic unit required an oral medicine consultation as the patient complained of severe oral ulceration. Intraoral examination revealed extensive ulceration of the buccal mucosa, hard palate, tongue and floor of the mouth (Fig. 1), compatible with a diagnosis of chemically induced oral ulceration as a result of an intentional acute exposure to sulphuric acid. Following acute admission total parenteral nutrition was administered for eight days and a chest drain was placed for ten days. Systemic antibiotics (cefazolin, $500 \mathrm{mg}$ every eight hours for ten days) and analgesic (ibuprofen, 400 mg every eight hours) were provided. The oral ulceration was initially treated with systemic corticosteroids (betamethasone, $4 \mathrm{mg}$ once a day for three days) followed by topical corticosteroids (betamethasone, $0.5 \mathrm{mg}$ in $10 \mathrm{ml}$ of water as mouthwash three times daily for ten days) and systemic antifungals (fluconazole, $50 \mathrm{mg}$ once 
a day for ten days). All oral lesions healed within 28 days, the only longstanding abnormalities being some local scarring and loss of papillae on the lateral border of the tongue.

\section{DISCUSSION}

Exposure to toxic substances is a rare, but potentially serious, cause of traumatic ulceration of the oral mucosa. Human exposure to toxic agents can be classified as unintentional (accidental), intentional (self inflicted) and others. ${ }^{5}$ Agents associated with oral chemical burns include dental materials commonly used by dentists, medication used to treat local or systemic disease, recreational drugs and non-pharmaceutical substances.

Oral mucosal damage due to chemicals is often the result of an unintentional therapeutic error by clinicians during dental procedures as a wide range of dental agents can cause mucosal harm ${ }^{6-}$ ${ }^{23}$ (Table 1). Restorative dental materials, antiseptic preparations and endodontic products are among the most common caustic agents being used daily by dentists during routine dental treatments. Among all dental materials, liquids are most likely to cause chemical oral burns because they can be difficult to manipulate.

Unintentional self-inflicted therapeutic error due to patients' improper application of medication (eg aspirin and derivates) is quite common. ${ }^{24-33}$ Most cases are caused by aspirin and derivates when sucked, ${ }^{25}$ applied as a gel, ${ }^{26}$ mouthwash, ${ }^{27}$ powder ${ }^{28}$ or as a tablet next to an aching tooth in an attempt to alleviate pain. ${ }^{29-33}$ The low PH (3.5-5.0) of these products seems to be the origin of the mucosal damage. Other medications such as chlorpromazine, promazine ${ }^{15}$ and alendronate ${ }^{34,35}$ have been linked to mucosal damage of the upper aerodigestive tract when used contrary to the drug prescription and physician instructions.

Overzealous use of a variety of nonpharmaceutical substances ranging from antiseptic products to household and industrial products can lead to oral mucosa injuries. Self-treatment without seeking professional advice is a common cause of self-injury. There are numerous reports of adverse effects on the oral mucosa of over-the-counter products. They are widely available and often used

\section{Table 1 Reported toxic agents linked to chemical oral burns}

\section{CHEMICAL TOXIC SUBSTANCES}

UTILISATION/COMMENT

\section{DENTAL MATERIALS}

\section{Cavity varnish ${ }^{6}$}

Dentine bonding agent ${ }^{7}$

Phosphoric acid etching solutions ${ }^{8}$

lodine $^{9}$

Phenol (carbolic acid) ${ }^{9}$

Trichloroacetic acid ${ }^{10}$

Ferric sulphate ${ }^{11}$

Chromic acid ${ }^{13}$

Hydrofluoric acid ${ }^{14}$

Sodium hypochlorite ${ }^{16-20}$

Calcium hydroxide ${ }^{21,22}$

Formocresol ${ }^{21,12}$

Paraformaldehyde ${ }^{9}$

Arsenic $^{23}$
Restorative dental material (liquid/gel)

Restorative dental material (liquid)

Restorative dental material (gel/liquid) Antiseptic (liquid)

Antiseptic (liquid)

Astringent for gingival retraction (liquid) Astringent for gingival retraction (liquid) Antiseptic (therapeutic agent) (liquid) Porcelain and metal etching (liquid)

Root canal irrigant (liquid)

Used in restorative dentistry (cement)

Endodontic treatments (pulp medicament) (liquid)

Devitalising agents (liquid/paste)

Devitalising agents (paste)

\section{MEDICATIONS}

\begin{tabular}{l|l} 
Chlorpromazine $^{15}$ & Antipsychotic drug \\
Promazine $^{15}$ & Antipsychotic drug \\
Aspirin $^{24-33}$ & Non opioid analgesic \\
Alendronate $^{34,35}$ & Bisphosphonate
\end{tabular}

\section{NON-PHARMACEUTICAL SUBSTANCES}

\begin{tabular}{|c|c|}
\hline Mouthwashes ${ }^{36-40}$ & Antiseptic oral cavity (liquid) \\
\hline Hydrogen peroxide ${ }^{32,41-43}$ & Antiseptic (liquid) \\
\hline Gasoline $^{15}$ & Petroleum - derived mixture used ad fuel (liquid) \\
\hline Rubbing alcohol ${ }^{15}$ & $68.5-71.5 \% \mathrm{vol} / \mathrm{vol}$ of absolute alcohol (liquid) \\
\hline Battery acid ${ }^{15}$ & Sulphuric acid and water (liquid) \\
\hline Minard's liniment ${ }^{44}$ & Relief from pain (liquid) \\
\hline Arrack ${ }^{45}$ & Strong distilled spirit (liquid) \\
\hline Silver nitrate ${ }^{45}$ & Chemical cauterisation (liquid) \\
\hline Denture cleansers ${ }^{47,48}$ & Substances for cleaning dentures (tablet) \\
\hline Fresh fruit and fruit juices ${ }^{49,50}$ & Liquid \\
\hline Garlic $^{51}$ & Culinary and medicinal uses (vegetable) \\
\hline
\end{tabular}

DRUGS

Cocaine ${ }^{2-4}$

MDMA $^{52}$

Amphetamine $\mathrm{A}^{53}$
Recreational drug

Recreational drug

Recreational drug by patients to prevent and/or manage oral and dental conditions ranging from halitosis to the treatment of minor infections. Mouthwashes are used in a variety of clinical situations and often misused by the public leading to oral mucosa injuries. ${ }^{36}$ Some commercially available mouthwashes including Listerine ${ }^{37}$ and chlorhexidine based mouthwashes ${ }^{38}$ can result in mucosal lesions as a consequence of the presence and concentration of alcohol, additives and preservatives rather than the toxic effect of the agent itself. ${ }^{39,40}$

Hydrogen peroxide has often been reported to cause chemical burns of the oral mucosa ${ }^{41}$ when used as mouth rinse or via cotton swab as undiluted hydrogen peroxide solution $3 \% \%^{42}$ or at concentrations as low as $1 \%$. $^{43,32}$

Other substances that have been associated with mucosal injury include gasoline battery acid, ${ }^{15}$ Minard's Liniment ${ }^{44}$ (camphor 5.45\%; ammonia 3.5\% and turpentine 10,5\% W/W), silver nitrate, Arrack ${ }^{45}$ (a strong 40\% spirit distilled from figs) and topical anaesthetic gel with phenol and alcohol. ${ }^{46}$ The improper intra-oral use of dental cleanser tablets can result in mucosal injuries. ${ }^{47,48}$ Excessive consumption of fresh fruit and juices can also be harmful because of their acidic nature. ${ }^{49,50}$ Garlic and other herbs have been used for 
centuries as medical remedies. Bagan et al. reported a case of chemical oral burn caused by crushed garlic applied in the buccal vestibule overnight. ${ }^{51}$

Intentional toxic exposure in suicide attempts are rare but are associated with the most severe sequelae. ${ }^{5}$ Ingestion of alkaline or acid chemicals can produce various injuries to the aerodigestive tract ranging in severity from mild to fatal. ${ }^{52}$

Recreational drugs can also lead to oral lesions (Table 1). Cocaine is often applied to gingiva or to the alveolar mucosa to test the drug's purity and can be used to relieve the pain of cluster headaches. ${ }^{2-4}$ Other recreational drugs such as methylenedioxymethamphetamine (MDMA) ${ }^{52}$ and amphetamine in association with cocaine ${ }^{53}$ have been reported as causes of mucosal ulceration and periodontitis following oral application.

Chemical irritants cause oral mucosal damage via a variety of mechanisms such as direct damage via their acidic or alkaline nature. The organic and inorganic acids tend to bind with epithelium (tissue) proteins and denature the proteins of the cells leading to coagulative necrosis of the cells, with the coagulum tending to limit the penetration of the acid. The alkalis dissolve protein and collagen leading to saponification of fatty tissue and liquefactive necrosis. The saponofication/ liquefactive necrosis does not limit tissue penetration thus alkalis have the potential to cause more extensive damage than acids, allowing deeper penetration of the chemical. In instances of prolonged contact, some agents can be absorbed and may cause systemic effects. ${ }^{26}$

Regardless of the cause, the clinical features of chemically induced traumatic ulceration are generally similar. In general, the more caustic the agent is and the longer the exposure, the greater the tissue damage.

Chemically induced oral ulceration can affect any oral mucosal site but more commonly affects the labial and buccal mucosae. The severity of chemical oral burns usually ranges from mild to moderate lesions, however, sometimes they can result in life-threatening damage and residue.

Following exposure to the caustic agent there is immediate erythema and oedema of the oral mucosa and gingiva, with later formation of white slough pseudomembrane covering the underlying ulceration. The ulceration has an irregular border and bleeds easily. If there is involvement of the ductal openings of the major salivary glands a transient obstructive sialadenitis can arise. ${ }^{47}$ Subsequent scarring of affected sites can cause permanent obstruction, chronic sialadenitis and require surgical excision of the gland. ${ }^{55}$

The diagnosis of chemically induced oral ulceration is usually based upon clinical history and features. A history demonstrating chronological correspondence between a potential causative agent and the onset of the ulceration greatly aids diagnosis. ${ }^{56}$ Histopathological examination of lesional and perilesional tissue is rarely indicated unless it is difficult to obtain an adequate history (this may be intentionally unclear or confusing) or if there is a suspicion of malignancy or potential malignancy. ${ }^{45}$ The histopathology of chemically induced ulceration typically demonstrates areas of focal coagulative necrosis of the epithelium, ulceration, intra- and extra-cellular oedema and a sub-epithelial acute inflammatory infiltrate.

The treatment of oral ulceration due to chemical trauma principally requires identification and removal of the toxic agents. Most chemical burns are characterised by mild to moderate tissue damage that heals spontaneously within seven to 15 days without scarring, ${ }^{57}$ thus only palliative and symptomatic treatment such as gentle plaque control and rinsing with a topical anaesthetic is required..$^{58} \mathrm{In}$ instances of more severe tissue damage, non-potent topical corticosteroids (eg triamcinolone) in a protective vehicle of carboxymethylcellulose may be helpful. ${ }^{59} \mathrm{~A}$ bland diet can also be beneficial. ${ }^{57}$ Lesions occurring after extensive exposure to strong caustic agents may require local debridement and antibiotic therapy. ${ }^{15}$

1. Porter SR, Leao J C. Review article: oral ulcers and its relevance to systemic disorders. Aliment Pharmacol Ther 2005; 21: 295-306.

2. Gandara-Rey J M, Diniz-Freitas M, Gandara-Vila P, Blanco-Carrion A, Garcia-Garcia A. Lesions of the oral mucosa in cocaine users who apply the drug topically. Med Oral 2002; 7: 103-107.

3. Blanksma C J, Brand H S. Cocaine abuse: orofacial manifestations and implications for dental treatment. Int Dent J 2005; 55: 365-369.

4. Kapila Y L, Kashani H. Cocaine-associated rapid gingival recession and dental erosion. A case report. J Periodontol 1997; 68: 485-488.

5. Lai M W, Klein-Schwartz W, Rodgers G C, Abrams JY et al. 2005 Annual Report of the American
Association of Poison Control Centers' national poisoning and exposure database. Clin Toxicol (Phila) 2006; 44: 803-932.

6. Murrin J R, Abrams H, Barkmeler W W. Chemical burn of oral tissue caused by dental cavity varnish: report of a case. III Dent J 1978; 47: 580-581.

7. Harris J H. Soft tissue burns from a dentine bonding agent. Gen Dent 1991; 39: 350-351.

8. Regezi J A, Sciubba J J. Oral pathology: clinicalpathological correlations, 3rd ed. Philadelphia: WB Saunders, 1999.

9. Pindborg J J. Atlas of diseases of the oral mucosa. Philadelphia: Saunders, 1980.

10. Laskaris G, Scully C. Periodontal manifestations of local and systemic diseases: colour atlas and text. Berlin: Spinger, 2003.

11. Loe H. Reactions to marginal periodontal tissues to restorative procedures. Int Dent J 1968; 18: 759-778.

12. Ozcelik 0 , Haytac M C, Akkaya M. latrogenic trauma to oral tissues. Int J Prosthodont 2005; 18: 139-145.

13. Sugarman M M. Chromic acid burn. J Periodontol 1952; 24: 178-179.

14. Moore PA, Manor R C. Hydrofluoric acid burns. $J$ Prosthet Dent 1982; 47: 338-389.

15. Neville B W, Damm D D, Allen C M, Bouquot J. Oral and maxillofacial pathology. Philadelphia: Saunders, 2002

16. Hulsmann M, Hahn W. Complications during root canal irrigation-literature review and case reports. Int Endod J 2000; 33: 186-193.

17. Pashley E L, Birdsong N L, Bowman K, Pashley D H. Cytotoxic effects of $\mathrm{NaOCl}$ on vital tissue. J Endod 1985; 11: 525-528.

18. Gatot A, Arbelle J, Leiberman A, Yanai-Inbar I. Effects of sodium hypochlorite on soft tissues after its inadvertent injection beyond the root apex. J Endod 1991; 17: 573-574.

19. Oncag O, Hosgor M, Hilmioglu S, Zekioglu 0 et al. Comparison of antibacterial and toxic effects of various root canal irrigants. Int Endod J 2003; 36: 423-432.

20. Seltzer S, Farber PA. Microbiologic factors in endodontology. Oral Surg Oral Med Oral Pathol 1994; 78: 634-645.

21. Santos-Pinto L, Campos J A, Giro E M, Cordeiro $R$. latrogenic chemical burns caused by chemical agents used in dental pulp therapy. Burns 2004; 30: 614-615.

22. De Bruyne M A, De Moor R J, Raes F M. Necrosis of the gingiva caused by calcium hydroxide: a case report. Int Endod J 2000; 33: 67-71.

23. Smart E R, Barnes I E. Tissue necrosis after using an arsenical endodontic preparation: a case report. Int Endod J 1991; 24: 263-269.

24. Maron FS. Mucosal burn resulting from chewable aspirin: report of case. J Am Dent Assoc 1989; 119: 279-280.

25. Christensen J R. A soft tissue lesion related to salicylate treatment of juvenile rheumatoid arthritis: clinical report. Pediatr Dent 1984; 6: 159-161.

26. Sapir S, Bimstein E. Cholinsalicylate gel induced oral lesion: report of case. J Clin Pediatr Dent 2000; 24: 103-106.

27. Glick G L, Chaffee R B Jr, Salkin L M, Vandersall D C. Oral mucosal chemical lesions associated with acetyl salicylic acid. Two case reports. NYState Dent J 1974; 40: 475-478.

28. Dellinger T M, Livingston H M. Aspirin burn of the oral cavity. Ann Pharmacother 1998; 32: 1107.

29. Kawashima Z, Flagg R H, Cox D E. Aspirin-induced oral lesion: report of case. J Am Dent Assoc 1975; 91: 130-131.

30. Scopp I W. From the casebook - aspirin burn. NYJ Dent 1977; 47: 310.

31. Smith C J. An approach to dealing with mucosal damage. J Am Dent Assoc 1991; 122: 73-74.

32. Rawal S Y, Claman L J, Kalmar J R, Tatakis D N. Traumatic lesions of the gingiva: a case series. J Periodontol 2004; 75: 762-769.

33. Buck I F, Zeff S, Kalnins L, Heiser R A et al. The treatment of intraoral chemical burns. J Oral Ther Pharmacol 1965; 2: 101-106.

34. Gonzalez-Moles M A, Bagan-Sebastian J V. Alendronate-related oral mucosal ulcerations. J Oral Pathol Med 2000; 29: 514-518. 
35. Krasagakis K, Kruger-Krasagakis S, loannidou D, Tosca A. Chronic erosive and ulcerative oral lesions caused by incorrect administration of alendronate. J Am Acad Dermatol 2004; 50: 651-652.

36. Moghadam B K, Gier R, Thurlow T. Extensive oral mucosal ulcerations caused by misuse of a commercial mouthwash. Cutis 1999; 64: 131-134.

37. Bernstein M L. Oral mucosal white lesions associated with excessive use of Listerine mouthwash. Report of two cases. Oral Surg Oral Med Oral Pathol 1978; 46: 781-785.

38. Flotra L, Gjermo P, Rolla G, Waerhaug J. Side effects of chlorhexidine mouth washes. Scand I Dent Res 1971; 79: 119-125.

39. Gagari E, Kabani S. Adverse effects of mouthwash use. A review. Oral Surg Oral Med Oral Pathol Oral Radiol Endod 1995; 80: 432-439.

40. Kowitz G M, Lucatorto F M, Cherrick H M. Effects of mouthwashes on the oral soft tissues. J Oral Med 1976; 31: 47-50.

41. Fantasia J E, Damm D D. White mucosa. Chemical burn. Gen Dent 2001; 49: 265, 324.

42. Shetty K. Hydrogen peroxide burn of the oral mucosa. Ann Pharmacother 2006; 40: 351.
43. Rees T D, Orth C F. Oral ulcerations with use of hydrogen peroxide. J Periodontol 1986; 57: 689-692.

44. Isenberg S R, Hier LA, Chauvin P J. Chemical burns of the oral mucosa: report of a case. J Can Dent Assoc 1996; 62: 262-264.

45. Baruchin A M, Lusting J P, Nahlieli 0 et al. Burns of the oral mucosa. Report of 6 cases. J Craniomaxillofac Surg 1991; 19: 94-96.

46. Flaitz C M. Chemical burn of the labial mucosa and gingiva. Am J Dent 2001; 14: 259-260.

47. Murdoch-Kinch C A, Mallatt M E, Miles D A. Oral mucosal injury caused by denture cleanser tablets: a case report. Oral Surg Oral Med Oral Pathol Oral Radiol Endod 1995; 80: 756-758.

48. Bundgaard T. Chemical burns in the oral cavity and esophagus after accidental intake of a Steradent denture-cleansing tablet. Tandlaegebladet 1985; 89: 711-713.

49. Hulme A C, Rhodes M J C. Biochemistry of fruit and their products. New York: Academic Press, 1980.

50. Toyuz L Z G, Hille J J. A fruit mouth-wash chemical burn. Report of a case. Oral Surg Oral Med Oral Pathol 1984; 58: 290-292.

51. Bagga S, Thomas B S, Bhat M. Garlic burn as self- infliceted mucosal injury-a case report and review of the literature. Quintessence Int 2008; 39: 491-494.

52. Brazier W J, Dhariwal D K, Patton D W, Bishop K. Ecstasy related periodontitis and mucosal ulceration - a case report. Br Dent J 2003; 194: 197-199.

53. Parry J, Porter S, Scully C. Flint S, Parry M G. Mucosal lesions due to oral cocaine use. Br Dent J 1996; 180: 462-464.

54. Arevalo-Silva C, Eliashar R, Wohlgelernter J, Elidan J, Gross M. Ingestion of caustic substances: a 15-year experience. Laryngoscope 2006; 116: $1422-1426$

55. Varkey P, Tan N C, Chen H C. Corrosive injury of ora cavity - a rare presentation. J Plast Reconstr Aesthet Surg 2006; 59: 1110-1113.

56. Haring J I. Case \#8. Chemical injury. RDH 1996; 16: $12,38$.

57. Holmes R G, Chan D C, Singh B B. Chemical burn of the buccal mucosa. Am J Dent 2004; 17: 219-220.

58. Smith C J. An approach to dealing with mucosal damage. J Am Dent Assoc 1991; 122: 73-74.

59. Baruchin A M, Lusting J P, Nahlieli 0 et al. Burns of the oral mucosa. Report of 6 cases. J Craniomaxillofac Surg 1991; 19: 94-96. 